Paidéia, 2003, 13(25), 27-40

\title{
INTERNET: UM NOVO DESAFIO PARA OS EDUCADORES ${ }^{1}$
}

\author{
Rosane de Albuquerque dos Santos Abreu ${ }^{2}$ \\ Ana Maria Nicolaci-da-Costa \\ Pontifícia Universidade Católica do Rio de Janeiro
}

\begin{abstract}
Resumo: A penetração das tecnologias digitais na educação trouxe desafios para os educadores que demonstram já ter absorvido o uso dos computadores, mas parecem achar difícil lidar com a Internet. Uma revisão da literatura revela que seu uso é visto como mais ameaçador e complexo o que seria, em parte, causado por fatores emocionais. Contudo esses estudos não investígam fatores emocionais em profundidade, realizando-se a presente pesquisa com este objetivo. Foram entrevistadas dez professoras, ligadas a diferentes atividades em escolas que já usavam a Internet há pelo menos dois anos. A análise do discurso produzido durante as entrevistas mostrou: Embora tenham a Internet como instrumento de trabalho (pesquisas), seu uso para objetivos educacionais parece ser fonte de conflitos internos, porque representaria um potencial de mudanças radicais na pedagogia tradicional, vistas como ameaça ao seu papel tradicional como professoras. Elas desconhecem como ser educadoras numa sociedade em rede e isso gera muita ansiedade.
\end{abstract}

Palavras-chave: Computadores; Internet; Professores; Desafios; Conflitos.

\section{INTERNET: A NEW CHALLENGE FOR TEACHERS}

\begin{abstract}
Penetration of digital technologies in schools brought a challenge for educators. That use the computers but seem to find the Internet more difficult to deal with. Review of specialized literature points out that this seems more threatening and complex, partially because of emotional factors. But these studies do not investigate such emotional factors in depth, and this was the objective of the present research. Ten teachers, engaged in different school activities and using the Internet for the last two years, were interviewed. Analysis of their discourse showed. Even though they use the Internet instrumentally for work (research) purposes, its use for educational objectives seems be a source of internal conflicts, and represents a potential of radical changes in traditional pedagogy and, a menace to their traditional role as teachers. They do not know how to be educators in a networked society and this makes them very anxious.
\end{abstract}

\section{Keywords: Computers; Internet; Teachers; Challenges; Conflicts}

A comercialização da Internet, ocorrida em meados da década de 1990 , vem acirrando o processo de transformação social iniciado por aquela que vem sendo chamada de Revolução das Tecnologias da Informação (Castells, 1999; Nicolaci-da-Costa, 2002c). Muitas mudanças vêm acontecendo em função da penetração das novas tecnologias da informação em fábricas, escritórios, hospitais, bancos, lojas, escolas, etc. Assim sendo, estão em mutação os pro-

\footnotetext{
1 Artigo recebido para publicação em 07/04/03; aceito em 27/06/03.

${ }^{2}$ Endereço para correspondência: Rosane de Albuquerque dos Santos Abreu, Departamento de Psicologia da PUC-RJ, Rua Marquês de São Vicente, 225, Gávea, Rio de Janeiro, RJ, Cep 22543-900, E-mail: Rosane.Abreu@terra.com.br
}

cessos de trabalho, as relações produtivas e o próprio mercado de trabalho. Algumas atividades estão sendo extintas, passando a ser executadas pelas máquinas, outras estão se reestruturando e se adaptando ao uso das novas ferramentas e outras ainda estão surgindo em função das novas tecnologias digitais.

No que diz respeito à atividade que temos como objetivo analisar - a de educar - os impactos das tecnologias digitais vêm sendo observados desde uma época anterior à difusão da Internet, mais precisamente na década de 1980 , quando foram instaurados programas e políticas para a informatização da sociedade brasileira ou, usando a expressão atual, para a inclusão digital. Nascia, nessa época, o que 


\section{Rosane de Albuquerque dos Santos Abreu}

hoje chamamos de Informática Educativa, ou seja, a área de estudos que se preocupa com a inserção do computador no processo de ensino-aprendizagem dos conteúdos curriculares de todos os níveis e modalidades de educação (Almeida, 1987; Fagundes, 1988; Moraes, 1993, 1997; Oliveira \& cols, 1993; Valente, 1999; Valente \& Almeida, 1998).

As novas tecnologias digitais não são, no entanto, de fácil absorção pela maior parte dos educadores. Além dos impactos que elas vêm gerando sobre seus usuários como um todo (Costa, 2001; Leitão, 2003; Nicolaci-da-Costa, 1998, 1999, 2000, 2002a, 2002b; Romão-Dias, 2001; Zaremba, 2001), a literatura sobre o uso das tecnologias computacionais na educação sugere, como será discutido a seguir, que os educadores estão enfrentando dificuldades e conflitos adicionais. A análise dessa literatura revelou, no entanto, a necessidade de uma investigação mais aprofundada dessas dificuldades e conflitos. Para tanto foi realizada uma pesquisa exploratória. Os resultados dessa pesquisa permitiram identificar que esses problemas podem ser tanto de ordem externa, (como, por exemplo, os relativos ao domínio das novas tecnologias e às pressões que os educadores sofrem para adotá-las), quanto de ordem interna (como, por exemplo, aqueles relativos à redefinição do seu próprio papel como educadores).

\section{Reações dos professores ao computador e à Internet: uma breve revisão da literatura}

A literatura sobre o uso das tecnologias computacionais na educação é muito vasta. Vários são os focos de análise que classificam a produção em diversas categorias, tais como: relatos de experiências sobre a aplicação pedagógica dos computadores, reflexões teórico-filosóficas acerca dos efeitos dessa tecnologia, apresentação de novos produtos tecnológicos para a educação, etc. No que se segue serão analisados os trabalhos inseridos em uma categoria que desperta especial interesse: a dos trabalhos que focalizam as reações dos professores às tecnologias digitais. Estes podem ser subdivididos em dois grupos: aqueles que tratam das reações dos professores aos computadores e aqueles que investigam os impactos da Internet sobre os professores. Passemos à sua discussão.

\section{Professores e Computadores}

As reações dos professores à penetração dos computadores na esfera pedagógica estão descritas e analisadas em produções de dois tipos: trabalhos de cunho reflexivo e pesquisas que tomam os professores como sujeitos de investigação. Os mais interessantes para o propósito do presente estudo são os trabalhos de Felipe (2001), Sobrinho (1997) e Tosta e Oliveira (2000). Isso porque discutem as reações dos professores tomando como referência a própria visão destes, coletada em entrevistas, questionários e observações de suas práticas. Identificamos nesses trabalhos alguns aspectos convergentes que foram agrupados em três categorias: dificuldades dos professores em relação à aplicação dos computadores na educação, sentimentos vividos nesse processo e efeitos dessa aplicação na prática docente.

\section{Dificuldades}

As dificuldades parecem ser muitas. Sobrinho (1997) identifica algumas em relação às experiências de professores com a informática educativa. Em primeiro lugar, afirma que eles se sentem intimidados no contato com os computadores, pois percebem ser necessário um domínio mínimo da tecnologia (hardware e softwares) para orientar a utilização do computador em atividades pedagógicas. Mostra, também, que eles se preocupam com a variedade de produtos educacionais lançados constantemente no mercado e que deles exige um aperfeiçoamento contínuo. Uma outra dificuldade identificada por Sobrinho diz respeito à relação dos professores com os profissionais de informática, ou seja, aqueles (técnicos, ou especialistas em informática educativa) que cuidam dos laboratórios de informática das escolas. Os professores reclamam que as preocupações desses profissionais não estão necessariamente voltadas para o programa curricular da escola e sim para o trabalho com os conteúdos técnico-operacionais das máquinas. Ressentem-se, ainda, do fato de que as atividades desenvolvidas nos laboratórios atraem bastante $a$ atenção dos alunos e são consideradas mais empolgantes do que aquelas realizadas em sala de aula. Finalmente, Sobrinho demonstra que os professores se sentem desconfortáveis perante os alunos que possuem experiência nos recursos 
computacionais e dedicam sistematicamente longos períodos dos seus dias ao seu aperfeiçoamento. Esses alunos dominam a tecnologia com a qual os professores têm dificuldade de lidar.

Tosta e Oliveira (2000) parecem ter encontrado resultados semelhantes. Afirmam que muitos professores não utilizam o laboratório de informática por não saberem usar os computadores e alegam falta de tempo para aprender. Na opinião dos pesquisadores, o que ocorre na realidade é que tais educadores mostram-se resistentes às mudanças que o uso do computador demanda em sua rotina de trabalho na escola.

Vemos, portanto, que as dificuldades são de diferentes ordens e são enfrentadas de maneiras também diversas, provocando a emergência de sentimentos, muitas vezes confusos, alguns dos quais serão explorados abaixo.

\section{Sentimentos}

A identificação do sentimento de medo por parte dos professores parece ser unânime nos estudos mencionados acima. Felipe (2001), por exemplo, revela que os medos que o professor sente variam do medo do computador ao de ver sua autoridade ameaçada pelo fato de os alunos saberem muito mais do que ele.

Já Sobrinho (1997), analisando uma experiência de capacitação docente, identificou que muitos professores têm dificuldades para se abrir a novas experiências. Eles não conseguem se desprender da posição de docentes, não se arriscam, não soltam sua curiosidade, não mexem livremente nos programas e não se permitem errar. Toda essa inibição torna mais difícil superar o medo do computador e tem reflexos no momento em que levam suas turmas ao laboratório de informática.

Felipe (2001) ainda considera que o medo do novo, característico de qualquer processo de mudança, parece assumir maiores proporções na atualidade, pois está sendo exigido dos professores que, além de saber usar e aplicar a tecnologia, sejam, também, agentes de mudança educacional. Tal exigência, na opinião de Felipe, faz com que os professores sintam-se desconfiados, céticos, pois não conseguem vislumbrar que a informática educativa possa ser um mecanismo de mudança na educação. Ao contrário, temem que $o$ discurso da mudança pela informática possa afetar a sua importância e o seu papel, contribuindo ainda mais para a desvalorização do magistério. Apesar disso, Tosta e Oliveira assinalam que alguns professores têm:

\section{"a vontade de se informar e capacitar para a inserção da informática educativa, demons- trando uma postura favorável e mais aberta para se repensar o papel do professor numa realidade social e educacional da qual a tecnologia é parte" (2000, p. 12).}

Medos, incertezas, inseguranças e desejos parecem, portanto, estar presentes nas experiências dos docentes com os computadores. Esses sentimentos, aparentemente, influenciam suas decisões peđagógicas em relação à incorporação (ou não) dessa tecnologia ao processo educacional. Estudar os efeitos do uso do computador na prática docente tem sido, portanto, o objetivo de vários pesquisadores.

\section{Efeitos dos computadores na prática docente}

Para muitos estudiosos, a presença dos computadores na educação tem uma dimensão revolucionária. Baseados no que ocorreu em outros setores da vida contemporânea, estes estudiosos acreditam que o uso da tecrologia digital pode impulsionar a tão sunhada e necessária transformação da educação.

A respeito dos efeitos revolucionários do uso dos computadores na prática pedagógica e na dinâmica escolar, os trabalhos de Felipe (2001), Sobrinho (1997) e Tosta e Oliveira (2000) revelam um quadro não muito animador. Tosta e Oliveira (2000), por exemplo, não se sentem autorizados a afirmar que houve mudanças substantivas nem na organização e na pedagogia das escolas, nem nos processos de ensino-aprendizagem. O computador, segundo eles, não foi realmente incorporado à dinâmica escolar. O laboratório de informática funciona como um "anexo" que professores e alunos pouco freqüentam. Quando o fazem, é como se estendessem o espaço da sala de aula para o laboratório, sem as necessárias modificações.

Já Sobrinho (1997) conclui que os professores vêem as novas tecnologias apenas como facilitadoras do trabalho escolar e acreditam que não 


\section{Rosane de Albuquerque dos Santos Abreu}

há nenhuma necessidade de modificar seus modos de atuação ou suas concepções de ensino frente à entrada da tecnologia na escola. Tal conclusão revela que:

\begin{abstract}
"o movimento de hibridação tecnológica na escola tende mais para acomodar as inovações do que para configurar uma outra prática de ensino" (Sobrinho, 1997, p.149).
\end{abstract}

Em resumo, o que pesquisas, como as mencionadas acima, têm mostrado é que o computador foi "domesticado" pelo professor, ou seja, que este encontrou formas de usar a parafernália digital (aplicativos e os softwares educativos) de modo a preservar o seu controle no processo pedagógico. Assim, é o docente quem escolhe o software e a maneira de utilizá-lo. Como afirma Moraes (1997, p. 16), os computadores "continuam perpetuando o vetho ensino, "otimizando o péssimo"”.

Fica, portanto, evidente que os computadores foram, gradativamente, deixando de ser novidade e de ameaçar, para passarem a servir de apoio às antigas e bem conhecidas tarefas levadas a cabo por professores e alunos. Esse quadro, porém, parece ter sido desequilibrado após a comercialização da Internet em meados da década de 1990.

\section{Professores e a Internet}

Os estudos de Sobrinho (1997) deixam transparecer que, na percepção dos professores, a Internet tem uma dimensão mais revolucionária que os recursos computacionais anteriores e que ela é o único novo componente surgido para a escola.

Apesar disso, ainda são poucos os trabalhos sobre a Internet na educação que colocam os professores como foco de investigação. Nestes poucos trabalhos, dois são os principais eixos de análise da relação desses profissionais com a Internet: um deles cuida das experiências de capacitação docente, investigando como os professores estão se apropriando da rede mundial de computadores; o outro analisa como os professores estão usando os recursos da Internet para apoiar as atividades pedagógicas.

\section{Capacitação docente}

Apesar de em número reduzido, alguns trabalhos descrevem e analisam as experiências de capacitação docente para o uso da rede, apresentando novas metodologias e novos ambientes de aprendizagem que buscam transformar radicalmente a formação docente. Esses trabalhos também permitem entrever algumas reações dos professores ao explorarem a Internet e vivenciarem novas situações.

Um dos principais estudos sobre a capacitação docente é o realizado por Maçada, Sato e Maraschin (2001). Estas autoras relatam uma experiência de atualização de professores de matemática para a utilização de recursos da Internet (chat, ICQ, e-mail, lista de discussão). Além de descreverem a nova experiência, as pesquisadoras analisam as transformações cognitivas dos professores em função de suas experiências em um ambiente virtual de aprendizagem $e$ da experimentação de novas metodologias pedagógicas. Como resultados, identificam que os professores acabam por vivenciar um confronto entre 0 "velho" regime cognitivo escolar de recepção de conhecimentos prontos e o novo regime cognitivo da busca de conhecimentos e descobertas. Além disso, nos primeiros contatos com as novas tecnologias, os professores revelam sentir desconforto (ansiedade) e insegurança. Esses sentimentos, no entanto, gradativamente, vão dando lugar a outros, tais como a satisfação em superar os obstáculos encontrados. Na visão das pesquisadoras, tal constatação revela o papel da emoção como catalisadora e facilitadora dos processos cognitivos. Seu estudo, no entanto, não investiga esses fatores emocionais em maior profundidade.

\section{Utilização dos recursos da Internet}

Já os trabalhos que integram o segundo grupo mencionado anteriormente procuram identificar como os professores estão fazendo uso dos recursos da rede para apoiar suas atividades pedagógicas e revelam as estratégias por eles usadas para a apropriação desses recursos. Cruz (1999), por exemplo, estuda a forma como professores de dois cursos de pós-graduação utilizam a videoconferência. Mostra que, diante dos novos recursos, os docentes mantêm as suas "perfomances" tal qual em ambiente de sala de aula, ou seja, usam a videoconferência como uma tribuna para um discurso pedagógico de mão única. Somen- 
te aos poucos, flexibilizam sua prática, tornando-a mais adequada ao novo modelo. Esse processo de flexibilização, no entanto, é doloroso, difícil e gera muita resistência.

Tanto os estudos de Cruz (1999) quanto de Maçada, Sato e Maraschin (2001) permitem perceber o sofrimento, o medo e a dificuldade dos professores diante dos novos recursos da tecnologia em rede. Registram, também, algumas reações dos professores a esses sentimentos. Nada disso, no entanto, é analisado em profundidade.

Candeias (1998), porém, avança um pouco mais na investigação de como os professores têm concebido o trabalho docente a partir da entrada das novas tecnologias (NTs) nas escolas. Dizemos "avança" porque o pesquisador analisa comparativamente as representações de dois grupos de professores, coletadas a partir de questionários. Um grupo era composto por professores participantes do Programa Internet nas Escolas da cidade de Salvador e o outro por professores da rede municipal de ensino da mesma cidade, que não tinham contato sistemático com as NTs. Usando trabalhos das áreas da cognição social e das representações sociais como referencial teórico, Candeias investiga as representações que os professores fazem de seu próprio trabalho, bem como as que constroem a respeito das NTs. Conclui, entre outras coisas, que a presença das NTs na educação ainda não colocou em questão, de maneira efetiva e prática, a educação hoje desenvolvida. Isso fica evidente porque sua pesquisa não identifica diferença significativa entre a prática dos professores que têm experiência com as novas tecnologias e daqueles que não têm. Quanto aos primeiros, Candeias esclarece que esses resultados não significam que eles não conseguiram assimilar nada das NTs na educação ou que são conservadores e não deixam espaços para mudanças. Segundo ele, as práticas docentes não se alteram porque "a dimensão pessoal parece não ter sido levada em conta nos processos de implementação dessas tecnologias na educação" (Candeias, 1998 p. 116).

Candeias traz contribuições interessantes a respeito das representações do trabalho docente, do papel das NTs na prática pedagógica e destaca a importância de se levar em conta o que dizem os professores a respeito das NTs na educação. Porém, de maneira análoga a Cruz (1999) e Maçada, Sato e Maraschin (2001), prestam pouca atenção aos sentimentos, pensamentos e conflitos neles envolvidos.

Resumindo o que foi discutido acima, os trabalhos mencionados nesta seção se restringem a mostrar como os professores estão se capacitando para usar os recursos da rede e como os estão efetivamente usando em suas atividades profissionais. Aqui e ali identificam reações, conflitos e dificuldades de ordem interna que esses profissionais enfrentam mas não procuram investigá-los em maior detalhe.

\section{Objetivos}

A constatação de que a literatura atual pouco esclarece a respeito das repercussões subjetivas (ou seja, de ordem interna) das experiências ciberespaciais dos professores foi o que nos mobilizou a implementar um estudo exploratório com o objetivo de investigar o que pensam e sentem os professores que usam a Internet. Nossa intenção foi dar voz ao professor, ou seja, deixá-lo falar para que pudéssemos compreender suas dificuldades e conflitos diante da penetração social e educacional da Internet.

\section{Método}

\section{Sujeitos}

Critérios de recrutamento

Por ser um estudo de caráter exploratório, sobre uma problemática de ordem interna que requer aprofundamento e a respeito da qual, como já foi visto, muito pouco pode ser encontrado na literatura especializada, estabelecemos apenas dois critérios para recrutamento dos professores a serem entrevistados: que fossem usuários da Internet há pelo menos um ano e que exercessem alguma atividade pedagógica em escolas da cidade do Rio de Janeiro. Optamos por um número relativamente pequeno de sujeitos - dez professores - para que pudéssemos investigar o mais profunda e cuidadosamente possível suas dificuldades e conflitos diante da penetração da Internet na educação. Para o recrutamento dos sujeitos fizemos uso de indicações de profissionais conhecidos. 


\section{Rosane de Albuquerque dos Santos Abreu}

Perfil dos sujeitos recrutados

Os critérios de recrutamento e as indicações de potenciais sujeitos recebidos levaram a entrevistar dez mulheres. Isso não foi intencional. (Na realidade, devido à esmagadora superioridade numérica das mulheres no ambiente escolar, tivemos dificuldade em encontrar homens para entrevistar.) Todas as entrevistadas eram usuárias pessoais da Internet há pelo menos dois anos (embora nosso critério exigisse apenas um ano de uso). Todas tinham mais de 8 anos de magistério e suas idades variavam entre 29 e 52 anos. Das dez professoras entrevistadas, 8 eram regentes de alguma disciplina e, portanto, atuavam diretamente com alunos em sala de aula. As outras duas exerciam função de orientação educacional (fora da sala de aula), mas também tinham contato direto com os alunos dentro do ambiente escolar. Quase todas lecionavam em escolas que não possuíam laboratório de informática (nestas, havia computadores somente para os professores). Houve apenas duas exceções. Na maior parte dos casos, portanto, nenhum trabalho sistemático usando a rede era desenvolvido com os alunos. Todas as entrevistadas foram, no entanto, capazes de relatar experiências vividas com os alunos possuidores de computadores.

\section{Procedimento}

Como instrumento de coleta de dados, fizemos uso de entrevistas individuais, cujas perguntas foram formuladas a partir de um roteiro previamente elaborado. Os próprios sujeitos escolheram o local (a própria escola ou sua casa) e o horário da entrevista, que durou cerca de uma hora. Essas estratégias foram usadas para criar um clima descontraído e informal durante a entrevista de modo que os sujeitos se sentissem à vontade. Tal clima era essencial, pois necessitávamos que os sujeitos se soltassem para revelar suas dificuldades e seus conflitos. Com o seu consentimento, todas as entrevistas foram gravadas não somente para agilizar o registro das falas, como também para registrar a entonação de voz, as hesitações, os silêncios, os risos (ou risadas), etc. dos sujeitos.

$O$ roteiro de entrevista continha os pontos básicos a serem abordados e aprofundados quando necessário. Esses pontos foram organizados sob a for- ma de itens que serviam de lembretes para que o entrevistador formulasse as perguntas. Todas as perguntas foram formuladas durante a entrevista para que não soassem formais ou artificiais ${ }^{1}$. Inicialmente, eram coletados dados de identificação do sujeito: idade, formação, disciplina que leciona ou atividade que exerce na escola, tempo de magistério e instituição em que trabalha. Seguia-se um bloco de questões abertas que tinha por finalidade caracterizar o professor como usuário da Internet. Neste, eram abordados os seguintes pontos: razões iniciais para a conexão à Internet; motivos para seu uso rotineiro; tempo e freqüência de acesso à rede; para que e como usavam a Internet $e$, finalmente, as opiniões dos entrevistados sobre a Internet (apreciações, comentários). Um terceiro bloco de questões procurava investigar a visão e os sentimentos dos entrevistados sobre o uso da Internet na educação. Para tanto, o roteiro previa o levantamento de suas opiniões e comentários a respeito dos seguintes pontos: as consequiências da rede para a educação (vantagens e desvantagens); os efeitos da Internet na sala de aula (sobre alunos e sobre professores); e o uso da Internet na educação (facilidades e dificuldades).

\section{Análise dos Dados}

Os dados coletados foram analisados por meio das técnicas da análise do discurso, tal como propostas por Nicolaci-da-Costa (1989a, 1989b, 1994) e empregadas em inúmeras pesquisas (Leitão, 2003; Nicolaci-da-Costa, 2000, 2002a, 2002b; Romão-Dias, 2001; Zaremba, 2001). Após sua transcrição, as entrevistas foram lidas cuidadosamente. Durante essa leitura, foram agrupadas as falas dos sujeitos segundo os tópicos do roteiro. Realizou-se, então, uma comparação das respostas dadas por eles a cada um dos itens do roteiro (análise inter-sujeitos). A partir desse procedimento, foram identificados pontos recorrentes em suas respostas, pontos esses que passaram a ser considerados categorias de análise para leituras subseqüentes. Em uma etapa posterior, procedeu-se à leitura e análise do discurso de cada sujeito (análise intra-sujeitos), procurando identificar possíveis contradições e conflitos individuais. Desta lei-

\footnotetext{
' Sobre a construção desse tipo de roteiro de entrevista ver Nicolaccida-Costa, 1989a)
} 
tura, foram levantadas outras categorias que se juntaram àquelas anteriormente mencionadas. Foram feitas, portanto, várias leituras, tanto do conjunto das entrevistas, quanto dos discursos individuais. Tais procedimentos nos forneceram profundo conhecimento do material coletado e nos permitiram detectar, ao mesmo tempo, recorrências nas respostas de todos os entrevistados bem como inconsistências nas respostas individuais.

\section{Resultados e Discussão}

\section{Como as entrevistadas vêem a Internet}

\section{Instrumento de trabalho}

Todas as professoras entrevistadas, como já mencionado, têm computador em casa e são usuárias da Internet há pelo menos dois anos. Apesar de haverem comprado o computador por diferentes motivos, todas usam-no, principalmente, para fins acadêmico-profissionais. É isso o que nos diz, por exemplo, Rosa ${ }^{3}$ :

\section{"Eu precisava de um instrumento mais rápi- do para elaborar texto. Isso até a descoberta da Internet. Descobri que pela Internet eu poderia pesquisar"(Rosa).}

Já Maria teve um motivo diferente:

"Meu marido trouxe [o computador] para minha filha de presente. Eu comecei na base da brincadeira e gostei. Eu hoje não sei tra. balhar sem computador"(Maria).

Para a maioria das entrevistadas, como exemplificam esses depoimentos, o acesso à Internet aconteceu naturalmente, em decorrência de seu envolvimento com o uso dos recursos computacionais. Apenas uma entrevistada relatou uma experiência no sentido inverso, isto é, relatou haver comprado o computador pesssoal motivada pela sua experiência profissional com a Internet. Todas as entrevistadas comentaram, ainda, que o computa-

${ }^{3}$ Todos os nomes usados são fictícios para preservar a identidade dos sujeitos. dor e a Internet são instrumentos fundamentais para o exercício de sua atividade profissional e que, atualmente, não podem prescindir dessas ferramentas.

À exceção de uma, que se considera "fanática", todas as entrevistadas se caracterizaram como usuárias moderadas da Internet. A maioria acessa a Internet diariamente, de casa, para ler e-mails ou para fazer pesquisas relacionadas às suas tarefas. Para elas, a pesquisa é a atividade prioritária, como diz Sílvia:

"Eu faço pesquisa para tentar aprofundar mais as coisas que vou trabalhar e tentar ver outros caminhos"(Silvia).

Como a pesquisa é a atividade mais concorri$\mathrm{da}$, todas as professoras usam bastante os sites de busca, de universidades e aqueles relacionados às suas áreas de saber. Os bate-papos on-line parecem ser pouco freqüentados pelas entrevistadas. Somente duas dizem gostar e participar com frequêencia dos chats. As demais, apesar de usarem-nos eventualmente, dizem não gostar desse tipo de bate-papo. As listas e grupos de discussão também não são muito concorridos: somente três entrevistadas dizem estar inscritas em pelo menos uma lista ou grupo. Os jogos on-line não são sequer citados, com exceção de uma professora que diz adorar esse tipo de recurso.

É possível inferir, portanto, que o computador e a Internet são instrumentos de trabalho para estas professoras. Melhor dizendo, a Internet e o computador são, para elas, suportes técnicos ao trabalho docente, mesmo que, como sinalizamos acima, elas nem sempre estejam usando tais tecnologias para desenvolver atividades didáticas com seus alunos.

\section{Fonte de ameaça ou de magia?}

Segundo os depoimentos coletados, a Internet parece ser vista como uma nova realidade, um mundo novo carregado de mistério. Algumas entrevistadas atribuem-lhe características ameaçadoras e fantásticas, que provocam reações e sentimentos variados. Vejamos alguns depoimentos a respeito do significado da Internet:

"Eu acho que a Internet por si só não é nada. A Internet, só pela existência dela, ela tem um 
34 Rosane de Albuquerque dos Santos Abreu

monte de informação. Eu tenho horror daquilo, eu tenho verdadeira alergia. É tanta informação!" (Selma).

"[A Internet] ao mesmo tempo que me atrai, me assusta, porque não tem fim. A impressão que eu tenho é que não tem limite. É um mundo tão louco e tão mágico!" (Rosa).

"[A Internet] é um instrumento de trabalho fascinante, é um instrumento de pesquisa excelente, é um desafio" (Maria).

Estes e outros depoimentos revelam posições contraditórias em relação à Internet. Ao mesmo tempo em que ameaça, incomoda e horroriza, a Internet também fascina, desafia e estimula as professoras.

\section{Como as entrevistadas vêem a penetração da Internet na educação}

\section{Nova fonte de pressão}

A penetração da Internet no ambiente escolar vem sendo observada por nossas entrevistadas, que identificam novos comportamentos. por ela gerados nos alunos em sala de aula. Mesmo no caso das escolas que ainda não usam a Internet com os alunes, todas as professoras destacam algumas práticas discentes que atribuem ao uso que estes fazem da rede mundial de computadores. Tais práticas parecem estar pressionando-as a participar dessa nova realidade, desse novo mundo interconectado por computadores.

"Eu tenho um aluno que tem o linguajar da Internet. Ele entra todos os dias e usa os sites de bate-papo, tem uns códigos e às vezes ele coloca nas fichas de trabalho. Foi assim que eu percebi essa coisa da Internet" (Sílvia).

"Hoje em dia, quando você pede uma pesquisa pro aluno, a maioria que tem Internet pega, imprime tudo e te entrega.". (Maria Helena)

"Eu acho que os meninos estão usando a Internet em excesso. Chega um ponto que eles não sabem trabalhar em grupo com pessoas humanas, eles têm dificuldades no colégio, as coisas pra eles são altamente descartáveis, tudo eles deletam" (Maria).

Os alunos parecem ter mudado. Estão apresentando novos comportamentos que desorganizam as práticas docentes ou colocam em xeque a didática tradicionalmente usada. Como lidar com a prática do copiar/colar? O que fazer com a escrita escolar que está impregnada da forma da escrita dos e-mails e dos chats?

Esses novos comportamentos parecem gerar nas professoras a sensação de que as propostas pedagógicas vigentes estão inadequadas às exigências do novo tempo. Um tempo marcado pela presença da tecnologia digital em quase todas as atividades humanas e no qual já não é mais possível frear a sua penetração na educação. Vejamos o que Maria diz:

"Pra mim está cada vez mais difícil dar aula naquele sistema antigo que a gente chamava na linguagem popular de cuspe e giz. Eu tenho sempre que trazer uma coisa nova pra motivar o aluno" (Maria).

A maioria das entrevistadas revela que se sente motivada a enfrentar a Internet em função das experiências ciberespaciais dos alunos e dos novos comportamentos que estes apresentam em sala de aula. Além de se sentirem pessoalmente motivadas, percebem que outros professores também se mobilizam para enfrentar os desafios da rede.

"O que eu vejo dos meus colegas é que mesmo aqueles que nunca foram atraídos pelo computador estão vendo a necessidade de começar a saber usar o e-mail, acessar a Internet" (Rita).

Novidade que gera resistência ou enfrentamento

Todas as professoras entrevistadas - usuárias da Internet há pelo menos dois anos - identificaram posições de resistência em seus colegas no que se refere tanto ao uso do computador quanto da Internet. Elas, porém, julgam fazer parte de um outro grupo, um grupo que busca enfrentar os desafios das novas tecnologias da informação. Seus depoimentos sugerem, portanto, a existência de dois grupos de profes- 
sores, aqueles que encaram as novidades trazidas pela rede mundial de computadores e aqueles que lhe são explicitamente resistentes.

"Tem gente que não aceita, que é muito resistente. Eu concordo que o computador não é a solução de problemas, mas as pessoas que ainda não se motivaram por ele, relutam muito. Colocam que as pessoas estão querendo competir e aparecer em função de aceitarem a informática com bons olhos" (Elza).

"Existe uma resistência muito grande porque dá trabalho. Você usar o computador, dá trabalho porque você tem que fazer uma adaptação da tua aula, você tem parar, pensar, sair daquela coisa rotineira. A gente costuma reclamar muito que o aluno tem preguiça, mas o professor também tem." (Maria Helena).

Parece evidente que existe uma tensão entre os integrantes dos dois grupos e que a competição profissional está implícita nessas divergências. Os resistentes são vistos como profissionais acomodados, talvez "preguiçosos", como diz Maria Helena, que pararam no tempo e no espaço. Já os usuários das tecnologias digitais, como as nossas entrevistadas, se percebem curiosos, destemidos, críticos e criativos. Assim nos diz Silvia:

"Por eu ser curiosa, foi que eu comecei a entrar [na Internet]" (Silvia).

Maria ainda complementa:

"Eu gosto muito de novidade, eu não tenho medo. Eu sou fascinada por essa máquina" (Maria).

Apesar dessas características, as entrevistadas não deixam de perceber que o uso da Internet tem seu lado positivo e negativo e que sua aplicação na educação, além de requerer muito trabalho e investimento, gera muitas preocupações e dificuldades.

\section{Preocupações}

Os depoimentos coletados revelam que as principais preocupações das entrevistadas referem-se às consequiências humanas da facilidade de acesso a informações, da disponibilidade de serviços e da utilização de novos mecanismos de interação (e-mails, chats, etc) proporcionados pela Internet. Uma dessas preocupações é relativa à socialização dos alunos, uma das funções da educação escolar, como mostram Sílvia e Maria Helena:

"Eu tenho preocupação com os alunos tímidos. Esse aluno que não tem uma socialização legal, mas que no computador ele é uma fera. Entra nas salas e bate papo, porque ali ele näo tem que se mostrar. Cada vez mais ele vai se fechando" (Sílvia).

"Se o menino tem acesso [à Internet] $e$ isso está vindo cada vez mais cedo, isso passa a ser também um fator de socialização. Essa criança está tendo uma forma de conhecer o mundo, de se socializar que o adulto não teve. E se a função da escola é socializar, educar, formar. Se essas coisas não forem discutidas, elaboradas e trabalhadas na escola, pode haver um atropelamento" (Maria Helena)

A Internet é uma nova fonte de socialização e constatar esse fato parece desestabilizar as professoras, especialmente no que se refere ao seu papel neste processo. Mostram-se preocupadas com o possível isolamento das pessoas (a esse respeito, ver Nicolaci-da-Costa 2000, 2002a, 2002b), com as conseqüências sócio-psicológicas das novas práticas ciberespaciais, especialmente das relações não presenciais características do ambiente virtual. Rosa é porta-voz dessa preocupação com os relacionamentos virtuais manifestada pela maioria das entrevistadas.

"Até onde você pode confiar a coisa da Educação a uma tecnologia dessas, sem que haja a necessidade da presença de alguém ali junto. Tem horas que ele [o computador] se basta, que não precisa de alguém ensinando. Mas péra ai, tudo o que eu entendo por gente precisa da presença. Essas coisas me assustam um pouco, mas me atraem". 


\section{Rosane de Albuquerque dos Santos Abreu}

As práticas virtuais, que transformam radicalmente os relacionamentos humanos, preocupam porque desestabilizam os processos tradicionais de ensino-aprendizagem e geram novas situações pedagógicas que exigem posturas docentes inovadoras.

Outra preocupação revelada na maioria dos discursos diz respeito ao papel dos professores nos processos de transmissão de informações e construção de conhecimentos.

"A educação pra mim é algo vivo, é uma troca que a Internet não consegue dar. Ela pode dar a informação pura e simples, mas a coisa do ampliar, aprofundar, ela não consegue. Acho que a escola é quem dá a estrutura. Não tem como o computador competir com a troca e com o conhecimento de cada aluno e o bom senso com que o professor trata cada aluno individualmente ou em grupo. Não tenho medo do computador, ele não vai substituiro professor" (Silvia).

No que diz respeito à Internet apenas como um instrumento de transmissão de informações, a opinião das entrevistadas parece ser a de que ela cumpre seu papel independentemente do professor. No entanto, no que diz respeito ao processo de construção de conhecimentos, sua opinião é bem diferente. Neste caso, enfatizam a necessidade da presença do professor auxiliando o aluno. Os recursos de interatividade que conferem à Internet sua dimensão inovadora não são levados em conta pelas professoras, pelo menos em um primeiro momento. É como se, para elas, esses recursos não existissem para fins pedagógicos. É possível supor que tal postura possa estar encobrindo o medo, acima mencionado por Silvia, de serem substituídas pela máquina.

As entrevistadas ainda demonstram estar preocupadas com as implicações educacionais da facilidade de acesso a informações, propiciada pela Internet, e com a qualidade da informação veiculada pela rede. Vejamos o que nos diz Selma:

"As crianças usam a Internet para obter informação, mas é uma informação que não fica. Viajar na lnternet não necessariamente permite que a criança pare pra refletir sobre o que ele está vendo. $\dot{E}$ um monte de informação chegando e aquilo vem sem crítica. Esse peso de verdade que o computador tem, acho que ele é muito mitificado e esse peso da informação pura, sem nenhuma reflexão, porque a reflexão não está na máquina, está no indivíduo. Se o indivíduo não tem o hábito de refletir ele vai ficar amarrado à máquina" (Selma).

Para as entrevistadas, ter acesso à informação (e pode ser uma informação errada) não necessariamente quer dizer que o aluno (ou qualquer outra pessoa) construiu algum conhecimento. $O$ depoimento de Selma é um bom exemplo de que a Internet gerou nas entrevistadas um processo de reflexão sobre questões relativas à construção do conhecimento bem como sobre o seu papel e o da escola na Era da Informação. O modelo de ensino centrado na informação, característico da maioria das escolas, passa a ser questionado. O próprio professor questiona a sua prática e identifica a necessidade de mudanças. Rita deixa aflorar exemplarmente o conflito das entrevistadas diante da penetração da Internet.

"Informação hoje todos têm, quem é esse professor agora? O que ele vai ensinar? Tudo bem, a informação sempre esteve nos livros. $O$ aluno pode ir lá, ler, está tudo ali. Só que agora ele pode assistir um programa de tele. visão, ele pode participar de uma lista de discussão, tem sites onde ele pode tirar as dúvidas dele, ele pode acessar aquela informação que interessa a especialistas. Isso que ele tinha na relação dele com o professor, agora ele tem de outras formas" (Rita).

Esse e vários outros depoimentos sugerem que está difícil definir "quem é esse professor hoje". Em decorrência, alguns sentimentos ameaçadores aparecem nas entrelinhas dos depoimentos. Um deles é o sentimento de exclusão que surge de forma subjacente na fala de Rita. Tal sentimento vem associado ao medo da perda de poder, um poder que tradicionalmente estava no saber do professor, um "saber verdadeiro", aquele que o computador e a Internet parecem ameaçar. A sensação de estar perdido, de não 
saber o que fazer, também fica evidente na maior parte dos depoimentos, pois as novas tecnologias da informação estão desestabilizando os tradicionais modelos de ensino e, consequientemente, os modelos de professor. Passemos agora a examinar algumas dificuldades geradas pelo uso da Internet, tal como apontadas pelas entrevistadas.

\section{Dificuldades}

Apareceu, nas falas de todas as entrevistadas, a dificuldade de lidar com a defasagem existente entre as suas tentativas (muitas vezes frustrantes) de dominar as novas ferramentas tecnológicas e a facilidade e a rapidez com que os alunos manipulam essas tecnologias. $O$ depoimento de Martha exemplifica isso:

"Primeiro tudo que é novo é assustador, tudo que é novo precisa de um preparo especial. Segundo, esse novo é dominado com o máximo de facilidade pelas crianças e jovens. $\mathrm{Na}$ frente do computador eles não têm esse tipo de bloqueio porque eles estão conhecendo o mundo e conhecer o mundo significa conhecer o computador também. O professor, por ser sujeito formado, que já passou desse periodo de conhecer o mundo dessa forma, ele já fica em desvantagem em relação ao próprio aluno. O que acontece, historicamente a gente tem o professor que sabe e o aluno que não sabe. Como vai reverter isso? Um aluno que sabe e um professor que não sabe? Isso é complicado! Administrar uma coisa dessas é complicadíssimo" (Martha).

De uma forma ou de outra, todas as entrevistadas revelam a grande dificuldade que sentem para lidar com o computador e com a Internet. Seus discursos também deixam transparecer o quanto o novo desestabiliza, assusta e gera ansiedade, o que muitas vezes gera bloqueios e inibe o desejo de enfrentar os novos desafios.

Além da dificuldade no aprendizado das novas tecnologias, todos os depoimentos mostram a existência de outra mais complicada. Trata-se da dificuldade das entrevistadas em lidar com a constatação de que muitos alunos sabem mais do que elas e que, de um modo geral, eles aprendem a usar as ferramentas computacionais com muito mais facilidade. Fica evidente seu medo de perder a autoridade e o poder, já que ambos estão tradicionalmente associados ao saber. São sentimentos dolorosos, pois atingem diretamente o narcisismo docente. Mudar é muito difícil, pois envolve sofridas rupturas.

Como que para tornar as coisas ainda piores, as entrevistadas parecem associar a essas perturbadoras constatações o fato de a Internet ser incontrolável, ou seja, impossível de ser por elas dominada, o que dá lugar a uma outra fonte de inquietação. Elza a revela:

"Eu acho que uma aula no laboratório de informática por si só já é totalmente diferente de uma sala de aula, principalmente quando está usando a Internet. Eles estão tendo acesso a informações cada um com uma parte do site, ou cada um com um site, se você disponibilizar vários sites, cada um com uma informação e você com 40 [alunos] num laboratório, cada um querendo falar o que está encontrando. $\hat{E}$ uma aula movimentada, ela cansa muito mais e essa falta do controle fica evidente" (Elza).

A falta de controle característica da Internet parece desorganizar algo tradicional no processo ensino-aprendizagem. Até o seu aparecimento o professor sempre deu um jeito de estar no controle das ações pedagógicas. Mesmo nas propostas mais inovadoras, que dizem estar centradas na atividade do aluno (como, por exemplo, as propostas baseadas na abordagem construtivista), o professor mantém o controle do processo pedagógico. A Internet parece romper definitivamente com esse controle e trazer abaixo toda a sensação de segurança que revestia o professor em sua ação ${ }^{2}$.

Como pode ser constatado, os depoimentos que identificam as dificuldades enfrentadas pelas entrevistadas em relação à Internet apontam, novamente, para questões relacionadas ao saber. Parece, portanto, que um dos principais resultados das transformações geradas pela disseminação da Internet so-

\footnotetext{
${ }^{2}$ A esse respeito, ver Sobrinho (1997).
} 


\section{Rosane de Albuquerque dos Santos Abreu}

bre as professoras que entrevistamos foi o questionamento do que sabem. Dado que o que as professoras fazem depende do que sabem, podemos perceber quão sérios podem ser seus conflitos.

\section{Conclusões}

A revisão da literatura e os resultados de nosso estudo exploratório sugerem que a entrada da informática no ambiente escolar se deu em duas etapas distintas: a do ingresso do computador e a da chegada da Internet.

Os depoimentos das nossas entrevistadas parecem revelar que a primeira etapa já foi superada. Elas próprias que (como provavelmente muitos outros educadores), em um primeiro momento, se sentiram ameaçadas pelas dificuldades no domínio da nova tecnologia, pela inversão da tradicional hierarquia do saber (os alunos dominando o uso do computador com muito mais facilidade), pelos impactos da nova tecnologia em suas formas de pensar e, principalmente, pela perda do controle, conseguiram recuperar a confiança. $O$ computador foi por elas absorvido e domesticado.

Já no que diz respeito à chegada da Internet nas escolas, o quadro parece ser bastante diferente. Mesmo as professoras que participaram da nossa pesquisa - que, por serem usuárias pessoais da Internet, se vêem como representantes do grupo de professores que encaram o desafio do novo - se sentem desestabilizadas.

A Internet, mesmo para elas que dela já fazem uso pessoal rotineiro, representa uma ameaça muito maior do que os outros recursos computacionais. Embora já tenham dominado pelo menos seus usos mais corriqueiros, sentem-se pressionadas (principalmente pelos alunos, que sempre sabem muito mais do que elas) a se manterem atualizadas em relação aos novos recursos que não param de surgir. $O$ fato de os alunos usarem a Internet com maior facilidade tem ainda uma outra conseqüência bastante incômoda: a subversão da hierarquia do saber.

Os resultados mais interessantes da nossa pesquisa dizem respeito, no entanto, àqueles aspectos emocionais que foram apontados nos estudos revisados, mas ainda não foram objeto de maior aprofundamento por parte de pesquisadores em edu- cação: os conflitos psicológicos gerados pela necessária redefinição do papel do professor como agente de socialização e como facilitador da construção de conhecimento na nova sociedade em rede.

É justamente com relação a esses dois pontos que a maior parte dos conflitos das nossas entrevistadas vem à tona. Elas não sabem como usar a Internet numa sala de aula, pois um instrumento que abre as portas para a investigação sem rumo, que prescinde do professor como guia, entra em conflito radical com as propostas pedagógicas tradicionais. Como podem abrir janelas para o mundo sem perder o controle? Como podem competir com os atrativos da Rede? Serão elas imprescindíveis ou podem vir a ser substituídas por máquinas e/ou professores virtuais? Nos dias de hoje, quais são as diferenças entre informação e conhecimento? Qual o seu papel na transmissão da primeira e na construção do segundo?

Como esses questionamentos indicam, seu próprio papel como agentes de socialização, fontes de informação e peças fundamentais na construção do conhecimento parece estar ameaçado e isso lhes está gerando sofrimento. Apesar das dificuldades iniciais que tiveram com o computador, este pôde ser por elas domesticado, o que fez com que recuperassem a auto-estima e o controle sobre suas atividades escolares. Isso, no entanto, não lhes parece ser possível em relação à Internet. Esta coloca em xeque praticamente todos os aspectos da pedagogia tradicional, inclusive o papel do próprio professor.

"Quem é esse professor agora?", questiona uma das nossas entrevistadas. Ao fazê-lo, essa professora provavelmente dá voz àquele que parece ser 0 maior conflito das nossas entrevistadas e, muito provavelmente, dos educadores em geral. Reconhecem que o modelo tradicional de professor - que carregam dentro de si - está em vias de extinção, mas ainda não têm um novo modelo para colocar no seu lugar.

Este conjunto de resultados tem importantes implicações para a pesquisa em educação. Minimamente, deixa clara a necessidade de estudos que investiguem quais os conflitos internos que a Internet está gerando para os professores e como estes os estão enfrentando. Como a revisão da literatura já havia apontado e nossos resultados parecem tornar evidente, não há como deixar de lado os aspectos emocionais envolvidos no processo de ruptura com os 
modelos pedagógicos tradicionais, que foi introduzido pela Internet no ambiente escolar.

É, portanto, necessário investigar o mais ampla e aprofundadamente possível o que outros professores - usuários e não usuários pessoais da Internet, com diferentes inserções no continuum escolar - pensam e sentem. A Internet chegou para ficar e, ao que nossos resultados indicam, está provocando mudanças radicais na educação e muito medo, insegurança e ansiedade nos professores.

\section{Referências Bibliográficas}

Almeida, F.J. (1987). Educação e Informática: os computadores na escola. São Paulo: Cortez

Candeias, C.N.B. (1998). Significado do Trabalho e as Novas Tecnologias: uma visão a partir do trabalho docente. Dissertação de Mestrado, Faculdade de Educação - UFBA

Castells, M. (1999). A Sociedade em Rede. São Paulo: Paz e Terra

Costa, A.C.A. (2001). IRC: uma nova alternativa para as relações entre as pessoas. Dissertação de Mestrado. Departamento de Psicologia Clínica, PUC- RJ

Cruz, D.M. (1999). Aprender e Ensinar através da Videoconferência: percepções e estratégias de alunos e professores num ambiente tecnológico interativo. Tecnologia Educacional, 29 (145) 4-10.

Fagundes, L.C. (1988). Informática e Educação. Anais do VIII Congresso da Sociedade Brasileira de Computação (pp. 3-19), UFRJ/NCE: Rio de Janeiro.

Felipe, L.H.L. (2001). Informática e Educação: encontros e desencontros no ensino fundamental público. Dissertação de Mestrado, Departamento de Educação, PUC/RJ

Leitão, C. (2003), Os Impactos Subjetivos da Internet: reflexões teóricas e clínicas. Tese de Doutorado, Departamento de Psicologia, PUC- RJ

Maçada, D.L.; Sato, L.S. \& Maraschin, C. (2001). Educação sem Distâncias: uma experiência de convivência em ambiente digital de aprendiza- gem. Revista Brasileira de Informática na Educação, 9, 27-34.

Moraes, M.C. (1993). Informática Educativa no Brasil: um pouco de história. Em Aberto, 57, 17-26.

Moraes, M.C. (1997). O Paradigma Educacional Emergente. Campinas, SP: Papirus

Nicolaci-da-Costa, A.M. (1989a). Questões metodológicas sobre análise de discurso. Psicologia, Reflexão e Crítica, 4,103 - 108

Nicolaci-da-Costa, A.M. (1989b). Análise do Discurso em pesquisa Qualitativa. Anais da $18^{a} \mathrm{Reu}-$ nião Anual da Sociedade de Psicologia de Ribeirão Preto (501-504), São Paulo.

Nicolaci-da-Costa, A.M. (1994). A análise do discurso em questão. Psicologia: Teoria e Pesquisa, 10, 501-504.

Nicolaci-da-Costa, A.M. (1998). Na Malha da Rede: os impactos íntimos da Internet. Rio de Janeiro: Campus

Nicolaci-da-Costa, A.M. (1999). Caught in a World Wide Web: the Internet and the New Man. Em E. R. Larreta (Org), Media and Social Perception (pp.155-177). Rio de janeiro: UNESCO, ISSC, EDUCAM

Nicolaci-da-Costa, A.M. (2000). A tecnologia da intimidade. Anais do III Workshop de Fatores Humanos em Sistemas Computacionais (pp1-11), SBC (org), Porto Alegre: Autor.

Nicolaci-da-Costa, A.M. (2002a). Quem disse que é proibido ter prazer online? Identificando o positivo no quadro de mudanças atual. Psicologia: Ciência e Profissão, 22(2), 12-21

Nicolaci-da-Costa, A.M. (2002b). Internet: a negatividade do discurso da mídia vesus a positividade da experiência pessoal. À qual dar crédito? Estudos de Psicologia, 7, 25-35.

Nicolaci-da-Costa, A.M. (2002c). Revoluções Tecnológicas e Transformações Subjetivas. Psicologia: Teoria e Pesquisa, 18, 193-202.

Oliveira, C.D. \& cols (1993). Expectativas e reflexões sobre o uso do computador como recurso 
40 Rosane de Albuquerque dos Santos Abreu

pedagógico, Em J.A.Valente (Org.), Computadores e Conhecimento: repensando a Educação (pp. 386-394). Campinas: UNICAMP

Romão-Dias, D. (2001). Nossa plural realidade: um estudo sobre a subjetividade na era da Internet. Dissertação de Mestrado, Departamento de Psicologia, PUC/RJ.

Sobrinho, C. A. (1997). Informática no Ensino Fundamental: uma leitura de percepções docentes. Dissertação de Mestrado, PUC/RJ, Departamento de Educação.

Tosta, S.P \& Oliveira, M.A.M. (2000). O Computador não é uma lousa: as tecnologias de comunicação e informação e a prática docente, Anais $24^{a}$ Reunião Anual ANPED, www.anped.org.br

Valente, J.A. (1999). Mudanças na Sociedade, Mudanças na Educação: o fazer e o compreender, Em José Armando Valente (Org), O Computador na Sociedade do Conhecimento (pp.29-47). Campinas:UNICAMP/NIED

Valente, J.A. \& Almeida, F.J. (1998). Visão Analítica da Informática na Educação no Brasil: a questão da formação do professor. hitp:// www.proinfo.gov.br/biblioteca/txtie13doc.pdf

Zaremba, R. (2001). Escrevendo (ou seria 'teclando'?!) o homem do século XXI. Dissertação de Mestrado, Departamento de Psicologia, PUC-RJ 